\title{
VARIATION OF ANAL FIN EGG-SPOTS ALONG AN ENVIRONMENTAL GRADIENT IN A HAPLOCHROMINE CICHLID FISH
}

\author{
Anya Theis, ${ }^{1}$ Olivia Roth, ${ }^{2}$ Fabio Cortesi, ${ }^{1,3}$ Fabrizia Ronco, ${ }^{1}$ Walter Salzburger, ${ }^{1,4}$ and \\ Bernd Egger ${ }^{1,5}$ \\ ${ }^{1}$ Zoological Institute, University of Basel, Vesalgasse 1, 4051 Basel, Switzerland \\ ${ }^{2}$ GEOMAR, Helmholtz Centre for Ocean Research, Evolutionary Ecology of Marine Fishes, \\ Düsternbrooker Weg 20, 24105 Kiel, Germany \\ ${ }^{3}$ Queensland Brain Institute, University of Queensland, Brisbane, Queensland 4072, \\ Australia \\ ${ }^{4}$ E-mail: walter.salzburger@unibas.ch \\ ${ }^{5}$ E-mail: bernd.egger@unibas.ch
}

Running title:

VARIATION OF ANAL FIN EGG-SPOTS IN A CICHLID FISH

Keywords:

This article has been accepted for publication and undergone full peer review but has not been through the copyediting, typesetting, pagination and proofreading process, which may lead to differences between this version and the Version of Record. Please cite this article as doi: 10.1111/evo.13166.

This article is protected by copyright. All rights reserved. 
Male secondary sexual trait, natural selection, sexual selection, Cichlidae, Astatotilapia burtoni, Lake Tanganyika

\begin{abstract}
Male secondary sexual traits are targets of inter- and/or intrasexual selection, but can vary due to a correlation with life-history traits or as by-product of adaptation to distinct environments. Trade-offs contributing to this variation may comprise conspicuousness towards conspecifics versus inconspicuousness towards predators, or between allocating resources into coloration versus the immune system. Here, we examine variation in expression of a carotenoid-based visual signal, analfin egg-spots, along a replicate environmental gradient in the haplochromine cichlid fish Astatotilapia burtoni. We quantified egg-spot number, area, and coloration; applied visual models to estimate the trait's conspicuousness when perceived against the surrounding tissue under natural conditions; and used the lymphocyte ratio as a measure for immune activity. We find that (i) males possess larger and more conspicuous egg-spots than females, which is likely explained by their function in sexual selection; (ii) riverine fish generally feature fewer but larger and/or more intensively colored eggspots, which is probably to maintain signal efficiency in intraspecific interactions in long-wavelength shifted riverine light conditions; and (iii) egg-spot number and relative area correlate with immune defense, suggesting a trade-off in the allocation of carotenoids. Taken together, haplochromine eggspots feature the potential to adapt to the respective underwater light environment, and are traded-off with investment into the immune system.
\end{abstract}

\title{
INTRODUCTION
}

This article is protected by copyright. All rights reserved. 
Male secondary sexual traits constitute what are amongst the most conspicuous characters in animals and often play a key role in female choice and male-male competition (Darwin 1871; Espmark et al. 2000; Andersson 1994). Signals that aim to attract mating partners and to intimidate rivals are considered 'honest' if comprising a handicap and if being costly to display and/or to produce (Zahavi 1975; Iwasa et al. 1991; Iwasa and Pomianowski 1999; but see e.g., Számadó 2011 for other models of honest signaling). According to the 'handicap principle', displaying an honest signal should reflect the overall quality of its bearer (Zahavi 1975; Andersson 1994; Rowe and Houle 1996; but see Fisher 1930; Lande 1981; Kirkpatrick and Ryan 1991; Kokko et al. 2006). Importantly, variation in the expression of an honest signal is not expected to be purely under genetic control, but should instead correlate with life-history traits such as age, nutritional status, social status, or parasite load (Kodric-Brown and Brown 1984; van Noordwijk and de Jong 1986; de Jong and van Noordwijk 1992). Further, phenotypic divergence in such signals can emerge as by-product of adaptation to distinct environmental niches (Nosil 2012), since the traits are expected to evolve to a point where viability costs balance out mating advantage (Endler 1978; Jennions et al. 2001). Thus, variation in visual, acoustic and chemical signals can be affected by a wide array of environmental parameters.

A key component in visual signaling is the conspicuousness of the signal as it influences the perceptibility of the visual signal to the potential receivers such as mates and intraspecific rivals, but also interspecific competitors and, in particular, predators (Endler 1992). High predation pressure is often accompanied by a reduction in conspicuousness of signal expression (Endler 1980; Stuart-Fox and Ord 2004; Schwartz and Hendry 2007), whereas reduced visibility may lead to increased conspicuousness of visual signals, most probably to maintain

This article is protected by copyright. All rights reserved. 
their function in intraspecific interactions (Marchetti 1993; Zahavi and Zahavi 1997; Kekäläinen et al. 2010; Dugas and Franssen 2011). However, especially in aquatic environments, reduced visibility can also decrease conspicuousness of visual signals, for example when intraspecific receivers reduce their responsiveness to visual signals and/or when investing into this costly trait is maladaptive (e.g., Seehausen et al. 1997, 2008; Wong et al. 2007; Luyten and Liley 1991; Maan et al. 2010; Boughman 2001). Additionally, the size, shape or coloration of visual displays can be influenced by the physical or chemical properties of habitats (e.g., Endler and Houde 1995; Hill and Montgomerie 1994; Moller 1995; Candolin et al. 2007). In case of carotenoid-based visual signals, for example, the expression might be directly influenced by the accessibility to food resources, since carotenoids cannot be synthesized de novo by animals and thus have to be obtained through food (Goodwin 1986). The conspicuousness of carotenoid based visual signals should therefore reflect the ability to feed successfully on carotenoid-rich food (Hill 1992) - or even more likely - to be an indicator of the bearer's health, since carotenoids are also used as antioxidants in immune responses (Lozano 1994, 2001; von Schantz et al. 1999; Svensson and Wong 2011; Simons et al. 2012). Consequently, using carotenoids for signaling instead of the immune system is considered to be costly. Under stressful conditions carotenoids may therefore primarily be invested into the immune response or, alternatively, they may be allocated to offspring (Sheldon and Verhulst 1996) or to other life-history traits such as general fitness (Smith et al. 2007) and survival (Pike et al. 2007).

Taken together, visual signals can be shaped by both, sexual selection and a broad range of environmental and physiological factors. Examining the contribution of environmental factors on signal expression in nature is challenging, though, but has been successfully 
studied with respect to color patterns in some species (Endler 1980). A promising set-up to study the influence of natural selection on color patterns consists of populations of a species displaying secondary male ornaments that occur, in replication, along a marked environmental gradient. Such a setting can be found in the haplochromine cichlid species Astatotilapia burtoni (Günther 1894), which occurs both in East African Lake Tanganyika and inflowing rivers. This generalist species displays typical haplochromine features such as sexual dimorphism, female mouthbrooding and egg-spots, i.e. a characteristic carotenoid-containing visual signal and evolutionary innovation (Goldschmidt and de Visser 1990; Salzburger et al. 2005; Santos et al. 2014). Egg-spots are ovoid markings on the anal fin of haplochromines primarily composed of two types of chromatophores (xanthophores and iridophores) (Salzburger et al. 2007; Santos et al. 2014) (Fig. 1A). In male haplochromines egg-spots consist of a conspicuously colored yellow, orange or reddish inner circle and a transparent outer ring (Wickler 1962). The function of anal fin egg-spots has initially been attributed to female choice (Wickler 1962; Hert 1989, 1991; Couldridge 2002) or - more recently in the species examined here - to male-male competition (Theis et al. 2012, 2015). Astatotilapia burtoni exhibits a lek-like polygynandrous mating system, with only dominant males gaining access to territories as well as to females (Fernald and Hirata 1977). Moreover, egg-spots appear to play a pivotal role in interactions among males, as they appear to have an intimidating effect in A. burtoni (Theis et al. 2012). In both female choice and male-male competition, males are expected to benefit from adapting signal conspicuousness to be effective within their respective environment. Indeed, most haplochromine cichlids from Lake Victoria display fewer but larger and hence, more conspicuous egg-spots in more turbid waters (Goldschmidt 1991). Contrarily, in Pundamilia pundamilia, also a haplochromine from Lake Victoria, populations show a trend

This article is protected by copyright. All rights reserved. 
towards less conspicuous egg-spots with respect to saturation and hue in more turbid waters (Castillo Cajas et al. 2012).

In this study, we focus on the natural variation of egg-spots within and among four lakestream systems of A. burtoni. Each replicate system consists of at least one population sampled from a stream flowing into Lake Tanganyika and one lake population sampled from a lake habitat close to the estuary of the respective stream (Fig. 1B). Note that all lake populations originate from the same lake, Lake Tanganyika, but represent replicates as they show genetic structuring (Theis et al. 2014). Previous work has demonstrated that populations from replicate lake-stream systems show similar adaptations to divergent selection regimes with regard to body shape and trophic morphologies (Theis et al. 2014). Importantly, the detected trait differences among populations do not reflect pure plastic responses to different environmental conditions, but have a substantial genetic component (Theis et al. 2014). Here, we first explored sex-specific differences in egg-spots by comparing egg-spot number, relative average area, relative total area and coloration inferred from photographs of fish. Due to the proposed function of egg-spots in male-male competition (Theis et al. 2012, 2015), males were expected to display more, larger and more intensely colored egg-spots compared to females. To ascertain habitat-specific differences, the same egg-spot characteristics were then compared among males of the different lake and stream populations. We hypothesized that egg-spot characteristics from replicate lake-stream systems would follow similar trajectories along this environmental gradient. We then examined how the underwater light environment and the status of the immune system affect the conspicuousness of male egg-spots. To this end, we measured immune activity of males and underwater light environments from lake and stream populations and asked whether these factors were associated with divergence in the egg-spot characteristics number, relative average area, relative total area and coloration based on photographs. Finally, reflectance and

This article is protected by copyright. All rights reserved. 
irradiance spectrophotometry and theoretical fish visual models were used to determine the color contrast between male egg-spots and the surrounding anal fin tissue under natural ambient light conditions. We hypothesized that males from longer wavelength shifted environments, and/or males experiencing less stress to the immune system, would display the most conspicuous egg-spots.

We found sex- and habitat-specific differences in egg-spots of A. burtoni. Males had more elaborate egg-spots compared to females, and are likely to use them as honest signals with the potential to adapt their conspicuousness according to underwater light environment and immune defense. This study provides novel insights into the highly complex interactions between sexual and ecological selection that influence the expression of male secondary visual signals.

\section{Materials and Methods}

\section{SAMPLING}

Astatotilapia burtoni specimens, underwater ambient light measurements and immunological data were obtained between June 2011 and August 2013 from the Southern part of Lake Tanganyika, Zambia. In total, we sampled at 11 locations from four lake-stream systems (Fig. 1B; for detailed description of these localities see Appendix I in Theis et al. 2014), resulting in a dataset comprising 643 individuals (for detailed information on sample sizes see Table S1). Fish were collected using hook and line fishing, minnow traps and/or gill nets under the permission of the Lake Tanganyika Research Unit, Department of Fisheries, Republic of Zambia.

This article is protected by copyright. All rights reserved. 


\section{EGG-SPOT MEASUREMENTS BASED ON PHOTOGRAPHS}

Before taking the photographs, the fish $\left(\mathrm{n}_{\text {females per population }}=6-39, \mathrm{n}_{\text {females total }}=204 ; \mathrm{n}_{\text {males per }}\right.$ population $=10-55, \mathrm{n}_{\text {males total }}=300 ;$ for detailed information on sample sizes see Table $\mathrm{S} 1$ ) were anaesthetized with clove oil (2 - 3 drops per liter water) to reduce stress of handling. Two standardized photographs per individual were taken, one in lateral position to measure body size, and one focusing on the anal fin for subsequent measurements of the egg-spot characteristics (Fig. S1). All images were taken on a grey card to allow for manual white balance. We used digital cameras (Canon EOS 400D, Canon EOS 550D or Nikon D5000) with an external flash (Nikon, Speedlight SB-24).

To assess body size of fish, we recorded 17 homologous landmarks on the full body photographs (for details see Muschick et al. 2012) in the program TPSDIG (v.2.11; Rohlf 2008) followed by a transformation into centroid size in MORPHOJ (v.1.05f; Klingenberg 2011). Centroid size was then used as the representative measure for body size. The photographs were further used to assess egg-spot number, relative average egg-spot area, relative total egg-spot area and egg-spot coloration. To this end, egg-spot and anal fin areas were measured using the lasso tool in Photoshop (Adobe Photoshop CS3 extended, v.10.0.1). The relative total egg-spot area was defined as the proportion of the anal fin area occupied by the pigmented egg-spot area. The relative average egg-spot area was calculated as the relative total egg-spot area divided by the relative number of egg-spots (a complete egg-spot was counted as 1 and incomplete egg-spots as 0.5; following Albertson et al. 2014) to avoid artifacts through smaller - still growing egg-spots - typically at the edge of the anal fin.

This article is protected by copyright. All rights reserved. 
In addition, egg-spots were assigned to one of six color categories by AT ranging from a faint, barely pigmented to an intense appearance. The color categories (referred to as coloration from here on) therefore describe the conspicuousness of egg-spots based on a combination of hue, saturation and brightness (representative photographs of the color categories are provided in Fig. S2). Since every specimen displayed more than one egg-spot, an average value was calculated for each individual. Although coloration was defined by a categorical measure, it reflected a continuous variable after calculating the average value across all egg-spots for each specimen.

The differences in egg-spot measurements based on photographs (number, relative average area, relative total area and coloration) were analyzed in two steps: (i) sex-specific differences of egg-spots in all populations combined and (ii) habitat-specific differences of egg-spots among males of lake and stream populations within each system.

In order to test for differences in egg-spot characteristics between females and males, we conducted sex-specific centering and scaling of the data with respect to centroid size. This was necessary since $A$. burtoni shows pronounced body size dimorphism between males and females (Fernald 1977). Our aim here was to compare average sized females to average sized males (and not same sized females and males). A generalized linear mixed model (GLMM) with Poisson distribution was used in the case of egg-spot number and normal linear mixed models (LME) with ANOVA comparison were used for relative average egg-spot area (square root transformation), total egg-spot area and coloration data. Analyses were conducted using the package LME4 (Bates et al. 2014) in $\mathrm{R}$ (version 3.0.3, R Core Team 2014), which was also used for all further statistical analyses. The linear models included population (separately for each sex) as a random effect and were combined with a random 
slope (the centered body size) in cases where this improved the model (based on ANOVA comparisons). Additionally to the fixed effect sex, the centered body size and/or the interaction thereof was added if necessary (for details on the models see Table S2A).

Before the habitat-specific differences in the egg-spot characteristics were analyzed in detail, we tested for the biggest differences among populations with regard to egg-spot phenotype in males. To this end, we conducted a principal component analysis (PCA) with the function PRCOMP of the R package STATS for the combined egg-spot characteristics (number, relative average area, relative total area and coloration). Due to the large sample size we calculated the mean PC loadings per population for graphical illustration.

Habitat-specific differences of egg-spot characteristics were then analyzed among males of lake populations in comparison to the corresponding stream populations. A generalized linear model (GLM) with Poisson distribution was used in the case of egg-spot number, and normal linear models (LM) were used for relative average area, relative total area and coloration (with square transformation) data. Additionally to the fixed effect population, we included body size as a fixed effect if it improved the model (for details on the models see Table S2B). To correct for multiple comparisons, the function GLHT from the package MULTCOMP (Hothorn et al. 2008) with mcp specification (population comparisons within system) was used, with a correction for variance heterogeneity (vcov argument with sandwich function of the package sandwich; Zeileis 2004, 2006) for the egg-spot characteristics number, relative average area and relative total area, but not for coloration.

\section{EGG-SPOT REFLECTANCE AND THEORETICAL FISH VISUAL MODELS}

This article is protected by copyright. All rights reserved. 
Theoretical fish visual models (Vorobyev and Osorio 1998; Vorobyev et al. 2001) from the perspective of $A$. burtoni were used to measure the color contrast (color distance; $\Delta \mathrm{S}$ ) between male egg-spots and the surrounding anal fin tissue under natural ambient light conditions. For this purpose, specimens were caught in 2013 from each locality $\left(\mathrm{n}_{\text {males per population }}=4-9\right.$, $\mathrm{n}_{\text {males total }}=45$ ) except for the populations ChL, Ch1 and Lf1 (for detailed information on sample sizes see Table S1). Immediately upon collection, fish were anaesthetized with clove oil (2 - 3 drops per liter water) and reflectance spectra of the second egg-spot and the area above the egg-spots on the anal fin of males (see Fig. 1A) were taken in the field using a JAZ Modular Portable Spectrometer (Ocean Optics; wavelength range $300-980 \mathrm{~nm}$ ) with an integrated, pulsed Xenon lamp module (OCOJAZ-PX) and an OCOWS-1 diffuse reflection standard according to the methods described in Gray et al. (2011). Between four to six reflectance spectra were taken per area and specimen. Spectral files were visually inspected and processed using the R package PAVO (Maia et al. 2013). Wavelengths were interpolated in $1 \mathrm{~nm}$ bins over a spectral range from 400 - $750 \mathrm{~nm}$. Spectra from egg-spot and fin measurements were combined and averaged for each individual. To account for the light environment under which egg-spots are viewed, we modeled color discrimination using natural illumination measurements for each population taken from their environment at different water depths (see irradiance measurements below; Fig. S3). Whereby, using natural illumination measurements as part of the model, allows us to recreate what egg-spot colors look like in their environment independent of where (natural environment, laboratory, etc.) the spectral reflectance measurements are taken (see e.g. Cortesi et al. 2015).

A. burtoni photoreceptors are arranged in a classical mosaic pattern with four double cone receptors surrounding a single cone (Fernald and Liebman 1980; Fernald 1981). The single cone expresses a short-wavelength sensitive (SWS) 'blue' pigment with a peak spectral sensitivity $\left(\lambda_{\max }\right)$ at

This article is protected by copyright. All rights reserved. 
$455 \mathrm{~nm}$, the shorter tuned double cone member expresses a middle-wavelength sensitive (MWS) 'green' pigment at $523 \mathrm{~nm} \lambda_{\max }$ and the longer tuned double cone member expresses a longwavelength sensitive (LWS) 'red' pigment at $562 \mathrm{~nm} \lambda_{\max }$ (Fernald and Liebman 1980). Members of double cones have previously been shown to contribute separately to color discrimination in some fishes (Pignatelli et al. 2010) and we therefore modeled A. burtoni as having a trichromatic visual system with a cone photoreceptor ratio of 1:2:2 (SWS:MWS:LWS) and a 0.05 LWS noise threshold for the Weber fraction $(\omega)$ (for similar approaches see Boileau et al. 2015; Cortesi et al. 2015). The visual model calculates $\Delta \mathrm{S}$ within the visual 'space' of the fish based on an opponent mechanism, which is limited by the noise of different photoreceptor types (Vorobyev and Osorio 1998; Vorobyev et al. 2001). Similar colors will result in low $\Delta \mathrm{S}$ values, whereas chromatically contrasting colors will result in high $\Delta \mathrm{S}$ values with $\Delta \mathrm{S}=1$ as the discrimination threshold (just noticeable difference; JND). We would like to note that we currently do not know how A. burtoni processes visual stimuli and that behavioral experiments are needed to comprehend what a change in JND beyond the discrimination threshold of 1 signifies. Similarly, behavioral experiments would be needed to assess whether the discrimination threshold varies depending on direction and position in the visual space. Moreover, due to the difficulty of measuring egg-spots in the field we were restricted in sample size, which did not allow for further statistical analyses. However, it is our best estimator in that the larger $\Delta \mathrm{S}$ is, the more likely it is that the signal can be distinguished, especially when visual information needs to remain reliable over distance in turbid water conditions.

\section{ASSOCIATION TESTS}

Finally, we tested for an association between egg-spot measurements based on photographs and underwater light environments (i.e. orange ratio) as well as immunological parameters. To this end downwelling irradiance was measured for each locality (except Lf1) at the surface and at the following depths: $10,20,30,40,50,70$ and $100 \mathrm{~cm}$, or to the deepest 
possible point within the interval. At each depth, we took five measurements using a JAZ modular portable spectrometer (Ocean Optics; wavelength range $300-980 \mathrm{~nm}$ ) with an OFRM25L05 optical fiber and a CC-3-UV-T cosine corrector attached. Before measurements, an OCOWS-1 diffuse reflection standard was used for relative calibration. All measurements were taken in July 2013 on clear days around noon (between 11:30 and 14:00). Spectral data were inspected and processed using the package PAVO (Maia et al. 2013) in R. Wavelengths were interpolated in $1 \mathrm{~nm}$ bins from 400 - $700 \mathrm{~nm}$, and five measurements from each depth level were averaged. As a measure for underwater light environments, irradiance data was transformed into orange ratio values. The orange ratio quantifies the relative transmission of long wavelength light by dividing the integral of $400-550 \mathrm{~nm}$ absorbance by the integral of $550-700 \mathrm{~nm}$ absorbance (Endler and Houde 1995). This ratio generally increases with depth and increasing turbidity, as short wavelengths are selectively scattered and absorbed (Levring and Fish 1956). For further statistical comparisons among the localities, the average change in orange ratio for each locality was calculated from the deepest available measurement divided by the number of $10 \mathrm{~cm}$ depth levels.

As an immunological measurement, the activity of the immune system that can be found under natural environmental conditions was determined in the field. We measured the lymphocyte ratio in the blood (lymphocyte count / (lymphocyte + monocyte counts)) to estimate the proportion of cells of the adaptive immune system. Measurements were taken during the dry season in July 2013 for all lake-stream localities except for ChL, Ch1 and Lf1. Blood samples were taken from the caudal vein $\left(n_{\text {males per population }}=6-22, n_{\text {males total }}=94\right.$; for detailed information on sample sizes see Table S1) and directly analyzed with a flow cytometer (BD Accuri C6 Flow Cytometer, Becton and Dickinson, Heidelberg, Germany). 
Immunological assays were performed according to protocols developed for sticklebacks (Scharsack et al. 2004, 2007a,b) with the modifications reported in Roth et al. (2011) as well as cichlid-specific settings as developed and described in Diepeveen et al. (2013). The distinction of blood cell types (lymphocytes vs. monocytes) was based on differences in their light scatter profiles (FSC - forward scatter, approximation for cell size; SSC - side scatter, approximation for cell complexity).

To test for an association between egg-spot measurements based on photographs, orange ratio and immune response, each egg-spot characteristic (size-corrected, if necessary) was used as response variable in a multiple regression on distance matrices (MRM) with 10'000 permutations using the $\mathrm{R}$ package ECODIST (Goslee and Urban 2007). The explanatory variables in the MRMs were pairwise differences in orange ratio, immune response and geographic distance. Note that the MRM excluded the populations ChL, Ch1 and Lf1 due to lack of underwater ambient light and/or immunological data. In addition to the global MRMs, we also conducted separate MRMs with each egg-spot characteristic as single response variable and one or two explanatory variables combined.

\section{Results}

\section{SEX-SPECIFIC DIFFERENCES IN EGG-SPOTS}

Egg-spot number was the only examined egg-spot characteristic that showed no differences between sexes but correlated positively with body size (GLMM: $\mathrm{z}_{\mathrm{sex}}=-0.52$, $\mathrm{p}_{\mathrm{sex}}=0.602 ; \mathrm{z}_{\mathrm{CS}}$ $\left.=9.43, p_{C S}<0.0001\right)($ Fig. 2A). The measurements on egg-spot areas revealed that males tended to have larger average egg-spot areas and a significantly larger total egg-spot area 
relative to their fin areas compared to females (Fig. 2A). Therefore sex, but not body size improved the model for both egg-spot area characteristics (LME comparison with ANOVA: relative average egg-spot area $-\chi_{\text {sex }}^{2}=3.4139, \mathrm{p}_{\mathrm{sex}}=0.0647 ; \chi_{\mathrm{CS}}^{2}=0.1485, \mathrm{p}_{\mathrm{CS}}=0.6999$; relative total egg-spot area $\left.-\chi_{\mathrm{sex}}^{2}=7.5488, \mathrm{p}_{\mathrm{sex}}=0.0060 ; \chi_{\mathrm{CS}}^{2}=0.0073, \mathrm{p}_{\mathrm{CS}}=0.9318\right)$. Male egg-spots showed way more intense coloration, which also increased faster with increasing body size compared to females (LME comparison with ANOVA: $\chi^{2}$ interaction sex:CS $=8.5799$, $\mathrm{p}_{\text {interaction sex:CS }}=0.0034 ; \chi_{\text {sex }}^{2}=41.691, \mathrm{p}_{\mathrm{sex}}<0.0001 ; \chi_{\mathrm{CS}}^{2}=11.757, \mathrm{p}_{\mathrm{CS}}=0.0006 ;$ Fig. $\left.2 \mathrm{~A}\right)$ (for graphs showing sex-specific correlations of body size and egg-spot characteristics see Fig. S4A; for sex-specific mean values with corresponding confidence intervals of each eggspot characteristic see Table S3A).

\section{HABITAT-SPECIFIC DIFFERENCES IN EGG-SPOTS}

The PCA revealed a clear separation between lacustrine and riverine populations within the lake-stream systems, except for the four populations of the Kalambo system, which clustered together (Fig. 3A). The other three systems - Chitili, Lufubu and Lunzua - were separated into lake and stream populations along principal component 1 ( $\mathrm{PC} 1$, explaining $46 \%$ of the variance) and PC2 (explaining 32\% of the variance) (for detailed information on proportions of variance and averaged PC loadings see Table S4). Lake populations generally showed greater egg-spot numbers compared to stream populations. Stream populations had a larger relative average egg-spot area and more intense coloration, as well as a larger relative total egg-spot area in the case of Lf1.

The more detailed analyses for each egg-spot characteristic separately showed similar overall trends as the PCA results, but revealed lake-stream system-specific differences. The

This article is protected by copyright. All rights reserved. 
analysis of egg-spot number among populations within systems revealed that more upstream populations had significantly fewer egg-spots in the rivers Lufubu and Lunzua, but not in Kalambo and Chitili (GLM with correction for multiple comparisons: LfL - Lf2: $\mathrm{z}=3.873$, p $=0.0011 ;$ Lf1 - Lf2: $\mathrm{z}=4.616, \mathrm{p}<0.0001 ; \mathrm{LzL}-\mathrm{Lz} 1: \mathrm{z}=5.114, \mathrm{p}<0.0001$; only significant values are presented in the text, for all population comparisons within systems see Table S3D and for all population-specific mean values with corresponding confidence intervals for each egg-spot characteristic see Table S3B) (Fig. 2B). The model for egg-spot number also revealed an increase in egg-spot number with increasing body size of the males (GLM: $\mathrm{z}=$ $6.985, \mathrm{p}<0.0001$; population-specific correlations of body size and egg-spot characteristics are shown in Fig. S4B).

The relative average egg-spot area increased with larger distance from the lake within the Lufubu and the Lunzua systems and between two riverine populations of the Kalambo River (LM with correction for multiple comparisons: Ka1 - Ka3: $z=-2.997, p=0.0291$; LfL - Lf2: $z=-4.736, p<0.0001 ;$ LzL - Lz1: $z=-6.470, p<0.0001)$ (Fig. 2B; Tables S3B, S3D). With increasing body size of the males the average egg-spots became smaller in relation to fin area $(\mathrm{LM}: \mathrm{t}=-9.680, \mathrm{p}<0.0001)($ Fig. S4B $)$.

Relative total egg-spot area was the only parameter that showed no divergence along the lake-stream gradient (Fig. 2B; Tables S3B, S3D). There was a trend of body size improving the model, indicating a correlation between body size and relative total egg-spot area (LM comparison with ANOVA: $\mathrm{F}=2.8532, \mathrm{p}=0.0923)$. Note, however, that this result was mainly influenced by the riverine Chitili population (Ch1), as without $\mathrm{Ch} 1$, the trend did not persist (LM comparison with ANOVA: $\mathrm{F}=0.4716, \mathrm{p}=0.4928)$. This most probably reflects the data better and therefore body size was excluded as a fixed effect in this case. However, 
there were differences among systems with respect to this trait, with the Lufubu populations showing larger relative total egg-spot area compared to the Chitili and Kalambo populations (LM with correction for multiple comparisons: Chitili - Lufubu: $\mathrm{z}=3.378, \mathrm{p}=0.0045$; Kalambo - Lufubu: $\mathrm{z}=4.712, \mathrm{p}<0.001$; only significant values are presented in the text, for all system comparisons see Table S3E and for system-specific mean values with corresponding confidence intervals see Table S3C) (Fig. 2B).

Based on our color categories, riverine populations showed more intense colored eggspots than lake populations in the Chitili Creek and in the Lunzua system (LM with correction for multiple comparisons: ChL - Ch1: $\mathrm{z}=-3.531, \mathrm{p}=0.0050$; LzL - Lz1: $\mathrm{z}=-$ 4.889, $\mathrm{p}<0.0001$ ) (Fig. 2B; Tables S3B, S3D). Additionally, egg-spot coloration showed a positive correlation with body size (LM: $t=12.283$, $\mathrm{p}<0.0001)$ (Fig. S4B).

The visual model revealed a higher egg-spot to fin contrast (i.e. larger color distance) in riverine populations compared to lake populations (except for the Ka2 population; Fig. 3B). This pattern was consistent when visual models were calculated with underwater ambient light profiles from different depths (i.e. $10 \mathrm{~cm}, 30 \mathrm{~cm}$ and maximal depth, see Fig. S5).

\section{ASSOCIATION TESTS}

The results of the underwater ambient light and immunological parameters are shown in Figure 4. Within systems, the underwater light environment in stream populations was characterized by higher orange ratio values when compared to lake populations (for detailed information on orange ratio values see Table S5; for underwater ambient light spectral curves see Supplementary Fig. S3). The proportion of lymphocytes showed higher values for stream 
populations compared to lake populations in the Lufubu and the Lunzua systems, but less variation for the populations from the Kalambo system (Fig. 4).

The MRMs indicated that the examined egg-spot characteristics were influenced to a different extent by the explanatory variables. Relative average egg-spot area and egg-spot number correlated with the proportion of lymphocytes. However, egg-spot coloration correlated with underwater light environment and relative total egg-spot area with geographic distance (Table 1, Table S6).

\section{Discussion}

In this study, we examine natural variation in a putative sexually selected trait, anal fin eggspots, in lake and stream populations of the haplochromine cichlid A. burtoni. Egg-spots constitute a carotenoid based signal that has been suggested to be an evolutionary innovation of haplochromine cichlids (Goldschmidt and de Visser 1990; Salzburger et al. 2005; Santos et al. 2014).

We first show that egg-spot phenotypes differ substantially between sexes, with females showing smaller and less colored egg-spots compared to the larger and more intensely colored egg-spots of males (Fig. 2A). The increased conspicuousness of egg-spots in males is most probably founded in their function. Egg-spots play an important role in strength assessment of a competitor and elicit an intimidating effect in male combats in A. burtoni (Theis et al. 2012), as well as in its congener A. calliptera (Theis et al. 2015). Interestingly, in some haplochromine species including A. burtoni and A. calliptera, also female individuals 
show egg-spots. To the best of our knowledge, no function for female egg-spots has been reported yet, and, additionally to the reduced area and less conspicuous coloration, the female egg-spots also lack the translucent, non-pigmented area around the egg-spots. This translucent ring is likely to enhance contrast of egg-spots in males (Tobler 2006). Reduction or absence of visual signals in females is most probably to decrease energy investment and to reduce conspicuousness towards predators. Alternatively, this might be a corollary of the necessity to invest most of their resources directly into offspring (Trivers 1972). In addition, sexual immune dimorphism could play a role, i.e. whereas males increase fitness through mating success, females need to invest more resources in their immune system as they gain fitness through longevity (Rolff 2002) and should benefit from allocating carotenoids to immune responses instead of a costly trait (Lozano 1994, 2001; Svensson and Wong 2011). The reduced conspicuousness of egg-spots in females due to a reduction in egg-spot area and coloration goes along with a generally more drab body coloration. Interestingly, fin and flank traits seem to be coupled in females of Lake Malawi cichlids, but showed two distinct clusters in males (Brzozowski et al. 2012). This developmental uncoupling might enable males to specifically alter the conspicuousness of the trait in dependence of e.g., status (Brzozowski et al. 2012). Our finding that egg-spots in A. burtoni are only reduced in area and coloration, but not in number between males and females, might be the result of a developmental constraint.

Among males within systems, there is a general trend of increasing conspicuousness of egg-spots from lake towards riverine populations, with the latter generally showing fewer, but larger egg-spots with a more intense coloration and a higher egg-spot to fin contrast (Figs. 3A, B). Within systems, this increase in conspicuousness is either connected with a change to 
more intense egg-spot coloration (Chitili; no data available for egg-spot to fin color distance), larger relative egg-spot area and higher egg-spot to fin contrast (Lufubu), a combination of all three factors (larger relative average egg-spot area, more intense egg-spot coloration and higher egg-spot to fin contrast; Lunzua) or absent (Kalambo) (Figs. 2B, 3B). Except for the Kalambo system, egg-spots were more conspicuous in areas where predation pressure is presumably lower, i.e. the stream localities. Astatotilapia burtoni supposedly experiences predation through piscivorous fishes, other aquatic predators (e.g., otters and snakes), and birds (e.g., kingfisher and cormorants), of which only the latter and some piscivorous fishes also chase regularly in upstream riverine localities. It has been shown that in areas with high predation pressure ornamentation and coloration is reduced or cryptic (Endler 1980; StuartFox and Ord 2004). Because predation pressure most probably correlates negatively with orange ratio in our study system, it is difficult to disentangle their relative influences. Eggspot conspicuousness could be lower in the lake localities because of higher predation pressure, or - maybe more realistically - increased egg-spot conspicuousness in riverine systems could serve to maintain signal transmission in underwater light environments with higher orange ratios (i.e. long wavelength shifted environments).

Turbidity in aquatic systems can either lead to an increase in the conspicuousness of visual signals, most probably to maintain their function (Dugas and Franssen 2011; Kekäläinen et al. 2010), or a decrease in conspicuousness, because intraspecific receivers responded less to visual signals (e.g., Seehausen et al. 1997, 2008; Wong et al. 2007; Luyten and Liley 1991). Both scenarios have been discussed in the context of egg-spots (Goldschmidt 1991; Castillo Cajas et al. 2012). These two hypotheses are not mutually exclusive, though, given that the expression of visual signals could be linked to the properties of the ambient light environment 
or, more general, the overall costs and benefits of carrying and producing the signal. With respect to egg-spot divergence, this would suggest a scenario of increasing egg-spot conspicuousness with increasing turbidity, as long as the benefit outbalances the costs. This corresponds to our finding of more intensely colored egg-spots and higher egg-spot to fin contrast in longer wavelength shifted environments, where also predation is expected to be lower. The reduced expression found in other haplochromine species could be due to the high costs involved in maintenance or due to the absorption of reddish signals in very turbid conditions or deep water (e.g., Seehausen et al. 1997, 2008). This could possibly explain the secondary loss of egg-spots in some deep-water lineages of Lake Malawi haplochromines (Salzburger et al. 2005), and the decrease in egg-spot conspicuousness in more turbid water in P. pundamilia (Castillo Cajas et al. 2012), as these examined populations occur in much deeper and more turbid habitats compared to our examined A. burtoni populations.

The costs involved in producing and maintaining carotenoid-based ornaments is often linked to immune defense. The relative cost of allocating carotenoid pigments to visual signals is likely to increase upon activation of an immune response, which involves carotenoids (Lozano 1994, 2001; Svensson and Wong 2011). For example, fishes experiencing high levels of stress show reduced immune responses, which may result in a decreased lymphocyte ratio (Ellsaesser and Clem 1986; Witeska 2005). Allocation of carotenoids to the immune response is, in these cases, likely to be beneficial for the immune system. However, if carotenoids are limited or if there is a metabolic constraint for carotenoid conversion, investing in the immune system would likely reduce the conspicuousness of carotenoid based visual signals. In support of this trade-off hypothesis we found that A. burtoni populations with a decreased lymphocyte ratio show smaller egg-spots and populations with high 
lymphocyte ratios possess fewer but larger and more conspicuous egg-spots. (Note, however, that a shift in the lymphocyte ratio could also imply that there are more monocytes present, which are the first line of the immune defense, or fewer lymphocytes, which are indicative of a recovery from a recent infection.)

The relative influence of underwater light environment and immunological parameters seem to vary among egg-spot characteristics. Egg-spot coloration most probably depends on underwater light environment (i.e., orange ratio), whereas egg-spot number and relative average egg-spot area rather correlate with immune defense (Tables 1, S6). In systems showing population-specific differences in relative average egg-spot area (Lufubu and Lunzua), the fewer but larger egg-spots of riverine populations result in the same relative total area as the many smaller egg-spots of lacustrine populations. Relative total egg-spot area was therefore the only parameter, which did not differ among populations within systems and, interestingly, did also not correlate with body size. However, there is an among-system variation in relative total egg-spot area, with populations from Lufubu showing a larger relative total egg-spot area compared to the Chitili and Kalambo systems. We would like to note here that the Lufubu populations are, genetically, the most distinct ones (Theis et al. 2014).

Overall, the association between egg-spot characteristics, environmental and immunological parameters suggests that the relative total egg-spot area is rather fixed within systems, whereas egg-spot number, relative average egg-spot area and egg-spot coloration seem to adapt to the respective environment. Likewise, in the guppy Poecilia reticulata, the area of the sexually selected orange spots was fixed, but brightness was affected by the environment through scarcity in dietary carotenoids supplied by algae (Grether et al. 1999). 
However, that carotenoid uptake as such would influence egg-spot conspicuousness is rather unlikely as $A$. burtoni feed mainly on algae, plant material and macroinvertebrates (Theis et al. 2014), which offer plenty of carotenoids. There might be other factors, though, which were not taken into account here, and that might influence egg-spot characteristics as well, e.g., other abiotic environmental factors, special biotic interactions and/or anthropogenic influences. Further, the results on the association between egg-spots, underwater light environment and immunological parameters should be taken with caution since correlations of data from the field are vulnerable to contain artifacts and are based on a few populations only. Nevertheless, our findings provide a first insight with respect to possible environmental and immunological factors influencing the egg-spot phenotype. The fact that different eggspot characteristics may be influenced by variable environmental factors illustrates that several replicates need to be examined to elucidate the causes for variation in such a complex trait. To which degree underwater light environment and/or immune response are involved in shaping egg-spot characteristics needs further examinations under controlled laboratory conditions.

In summary, egg-spots show sex- and habitat-specific differences in the haplochromine cichlid A. burtoni. Males possess more conspicuous egg-spots compared to females, and, within populations, larger males have more conspicuous egg-spots than smaller ones, both of which could be explained by their function in sexual selection. Further, males of three out of four examined lake-stream systems show similar shifts in egg-spot divergence, with riverine fish possessing fewer but larger and/or more intensely colored egg-spots compared to fish from the corresponding lake habitats. Moreover, the visual model revealed more conspicuous egg-spots in riverine populations as compared to lake populations. Taken together, egg-spots 
represent an honest trait, which shows the potential to adapt to differences in signal transmittance, and that is traded off with investment into the immune system. Our findings indicate that the expression of a visual signal to maximize both, survival and reproduction is a complex and sensitive equilibrium, which should always be interpreted in the context of several aspects of both, sexual and ecological selection.

\section{ACKNOWLEDGEMENTS}

We would like to thank the helpers in the field, Judith Bachmann, Astrid Böhne, Tania Bosia, Vasco Campos, Marco Colombo, Marie Dittmann, Simon Egger, Adrian Indermaur, Isabel Keller, Yuri Klaefiger, Julia De Maddalena, Nina Merdas, Florian Meury, Dario Moser, Marius Roesti, Jakob Weber and Marisa Zubler; Heinz H. Büscher and Gilbert Tembo and his crew for their logistic support in Zambia; the Lake Tanganyika Research Unit, Department of Fisheries, Republic of Zambia, for research permits; and Axios Review as well as Associate Editor Rafael Rodriguez for valuable feedback on this manuscript. This study was supported by grants from the Freiwillige Akademische Gesellschaft Basel (FAG), the Swiss Academy of Sciences (SCNAT) and the Swiss Zoological Society (SZS) to AT; the Volkswagen Stiftung and the German Research foundation (DFG) to OR; and the European Research Council (ERC, Starting Grant 'INTERGENADAPT' and Consolidator Grant 'CICHLID X'), the University of Basel and the Swiss National Science Foundation (SNF, grants 3100A0_138224 and 3100A0_156405) to WS.

\section{DATA ARCHIVING}

Data associated with this manuscript are deposited in Dryad under the DOI 10.5061/dryad.18j1h.2. 


\section{REFERENCES}

Andersson, M. 1994. Sexual Selection. Princeton University Press, Princeton, NJ.

Albertson, R. C., K. E. Powder, Y. Hu, K. P. Coyle, R. B. Roberts, and K. J. Parsons. 2014. Genetic basis of continuous variation in the levels and modular inheritance of pigmentation in cichlid fishes. Mol. Ecol. 23:5135-5150.

Bates, D., M. Maechler, B. Bolker, and S. Walker. 2014. lme4: Linear mixed-effects models using Eigen and S4. R package version 1.1-7, http://CRAN.R-project.org/package=lme4.

Boileau, N., F. Cortesi, B. Egger, M. Muschick, A. Indermaur, A. Theis, H. H. Büscher, and W. Salzburger. 2015. A complex mode of aggressive mimicry in a scale-eating cichlid fish. Biol. Lett. $11: 20150521$

Boughman, J. 2001. Divergent sexual selection enhances reproductive isolation in sticklebacks. Nature 411:944-948.

Brzozowski, F., J. Roscoe, K. Parsons, and C. Albertson. 2012. Sexually dimorphic levels of color trait integration and the resolution of sexual conflict in Lake Malawi cichlids. J. Exp. Zool. B.: Mol. Dev. Evol. 318:268-278.

Candolin, U., T. Salesto, and M. Evers. 2007. Changed environmental conditions weaken sexual selection in sticklebacks. J. Evol. Biol. 20:233-239.

Castillo Cajas, R. F., O. M. Selz, E. A. P. Ripmeester, O. Seehausen, and M. E. Maan. 2012. Species-specific relationships between water transparency and male coloration within and between two closely related Lake Victoria cichlid species. Int. J. Evol. Biol. 2012:1-12.

This article is protected by copyright. All rights reserved. 
Cortesi, F., W. E. Feeney, M. C. O. Ferrari, P. A. Waldie, G. A. C. Phillips, E. C. McClure, H. N. Sköld, W. Salzburger, N. J. Marshall, and K. L. Cheney. 2015. Phenotypic plasticity confers multiple fitness benefits to a mimic. Curr. Biol. 25:949-954.

Coulter, G. W. 1991. Lake Tanganyika and its life. Oxford University Press, Oxford, UK.

Couldridge, V. C. K. 2002. Experimental manipulation of male eggspots demonstrates female preference for one large spot in Pseudotropheus lombardoi. J. Fish. Biol. 60:726-730.

Darwin, C. R. 1871. The descent of man and selection in relation to sex. John Murray, London, UK.

de Jong, G., and A. J. Noordwijk. 1992. Acquisition and allocation of resources: genetic (co)variances, selection and life histories. Amer. Nat. 39:749-770.

Diepeveen, E. T., O. Roth, and W. Salzburger. 2013. Immune-related functions of the Hivep gene family in East African cichlid fishes. Genes, Genomes, Genet. 3:2205-2217.

Dugas, M. B., and N. R. Franssen. 2011. Nuptial coloration of red shiners (Cyprinella lutrensis) is more intense in turbid habitats. Naturwiss. 98:247-251.

Ellsaesser, C. F., and L. W. Clem. 1986. Haematological and immunological changes in channel catfish stressed by handling and transport. J. Fish. Biol. 28:511-521.

Endler, J. A. 1978. A predator's view of animal color patterns. In: Hecht, M. K., W. C. Steere, and B. Wallace (eds.), p. 319-364. Evolutionary Biology Volume 11. Plenum Press, New York and London.

Endler, J. A. 1980. Natural selection on color patterns in Poecilia reticulata. Evolution 34:7691.

Endler, J. A. 1992. Signals, signal conditions, and the direction of evolution. Am. Nat. $139: 125-153$

This article is protected by copyright. All rights reserved. 
Endler, J. A., and A. E. Houde. 1995. Geographic variation in female preferences for male traits in Poecilia reticulata. Evolution 49:456-468.

Espmark, Y., T. Amundsen, and G. Rosenqvist. 2000. Animal signals: signalling and signal design in animal communication. Tapir Academic Press, Trondheim, Norway.

Fernald, R. D. 1977. Quantitative behavioural observations of Haplochromis burtoni under semi-natural conditions. Anim. Beh. 25:643-653.

Fernald, R. D., and N. R. Hirata. 1977. Field study of Haplochromis burtoni: quantitative behavioural observations. Anim. Behav. 25:964-975.

Fernald, R. D., and P. A. Liebman. 1980. Visual receptor pigments in the African cichlid fish, Haplochromis burtoni. Vision Res. 20:857-864.

Fernald, R. D. 1981. Chromatic organization of a cichlid fish retina. Vision Res. 21:1749-1753.

Fisher, R. A. 1930. The genetical theory of natural selection. Clarendon Press, Oxford, UK.

Goldschmidt, T., and J. de Visser. 1990. On the possible role of egg mimics in speciation. Acta Biotheoretica 38:125-134.

Goldschmidt, T. 1991. Egg mimics in haplochromine cichlids (Pisces, Perciformes) from Lake Victoria. Ethology 88:177-190.

Goodwin, T. W. 1986. Metabolism, nutrition, and function of carotenoids. Ann. Rev. Nutrition. 6:273-297.

Goslee, S. C., and D. L. Urban. 2007. The ecodist package for dissimilarity-based analysis of ecological data. J. Statist. Software 22:1-19.

This article is protected by copyright. All rights reserved. 
Gray, S. M., F. L. Hart, M. E. M. Tremblay, T. J. Lisney, and C. W. Hawryshyn. 2011. The effects of handling time, ambient light, and anaesthetic method, on the standardized measurement of fish colouration. Canad. J. Fish. Aquat. Sci. 68:330-342.

Grether, G. F, J. Hudon, and D. F. Millie. 1999. Carotenoid limitation of sexual coloration along an environmental gradient in guppies. Proc. R. Soc. B. 266:1317-1322.

Günther, A. C. L. G. 1894. Descriptions of the reptiles and fishes collected by Mr. E. CoodeHore on Lake Tanganyika. Proc. Zool. Soc. Lond. 1893:628-632.

Hert, E. 1989. The function of egg-spots in an African mouth-brooding cichlid fish. Anim. Behav. 37:726-732.

Hert, E. 1991. Female choice based on egg-spots in Pseudotropheus aurora Burgess 1976, a rock-dwelling cichlid of Lake Malawi, Africa. J. Fish. Biol. 38:951-953.

Hill, G. E. 1992. Proximate basis of variation in carotenoid pigmentation in male house finches. The Auk 109:1-12.

Hill, G. E., and R. Montgomerie. 1994. Plumage colour signals nutritional condition in the house finch. Proc. R. Soc. B. 258:47-52.

Hothorn, T., F. Bretz, and P. Westfall. 2008. Simultaneous inference in general parametric models. Biometrical J. 50:346-363.

Iwasa, Y., A. Pomianowski, and S. Nee. 1991. The evolution of costly mate preferences. II. The "handicap" principle. Evolution 45:1431-1442.

Jennions, M. D, A. P Moller, and M. Petrie. 2001. Sexually selected traits and adult survival: a metaanalysis. Q. Rev. Biol. 76:3-36.

This article is protected by copyright. All rights reserved. 
Iwasa, Y., and A. Pomianowski. 1999. Good parent and good genes models of handicap evolution. J. Theor. Biol. 200:97-109.

Kekäläinen, J., H. Huuskonen, V. Kiviniemi, and J. Taskinen. 2010. Visual conditions and habitat shape the coloration of the Eurasian perch (Perca fluviatilis L.): a trade-off between camouflage and communication? Biol. J. Linn. Soc. 99:47-59.

Kirkpatrick, M. and M. J. Ryan. 1991. The evolution of mating preferences and the paradox of the lek. Nature 350:33-38.

Klingenberg, C. P. 2011. MorphoJ: an integrated software package for geometric morphometrics. Mol. Ecol. Res. 11:353-357.

Kodric-Brown, A., and J. H. Brown. 1984. Truth in advertising: the kinds of traits favored by sexual selection. Am. Nat. 124:309-323.

Kokko, H., M. D. Jennions, and R. Brooks. 2006. Unifying and testing models of sexual selection. Annu. Rev. Ecol. Syst. 37:43-66.

Lande, R. 1981. Models of speciation by sexual selection on polygenic traits. Proc. Natl. Acad. Sci. USA 78:3721-3725.

Levring, T., and G. R. Fish. 1956. The penetration of light in some tropical East-African waters. Oikos 7:98-109.

Lozano, G. A. 1994. Carotenoids, parasites, and sexual selection. Oikos 70:309-311.

Lozano, G. A. 2001. Carotenoids, immunity, and sexual selection: comparing apples and oranges? Am. Nat. 158:200-203.

This article is protected by copyright. All rights reserved. 
Luyten, P. H., and N. R. Liley. 1991. Sexual selection and competitive mating success of males guppies (Poecilia reticulata) from four Trinidad populations. Beh. Ecol. Sociogiol. 28:329-336.

Maan, M. E., O. Seehausen, and J. J. M. van Alphen. 2010. Female mating preferences and male coloration covary with water transparency in a Lake Victoria cichlid fish. Biol. J. Linn. Soc. 99:398-406.

Maia, R., C. M. Eliason, P.-P. Bitton, S. M. Doucet, and M. D. Shawkey. 2013. pavo: an R package for the analysis, visualization and organization of spectral data. Methods Ecol. Evol. 4:906-913.

Marchetti, K. 1993. Dark habitats and bright birds illustrate the role of the environment in species divergence. Nature 362:149-152.

Moller, A. P. 1995. Sexual selection in the barn swallow (Hirundo rustica). V. Geographic variation in ornament size. J. Evol. Biol. 8:3-19.

Muschick, M., A. Indermaur, and W. Salzburger. 2012. Convergent evolution within an adaptive radiation of cichlid fishes. Curr. Biol. 22:2362-2368.

Nosil, P. 2012. Ecological Speciation. Oxford University Press, Oxford, UK.

Pignatelli, V., C. Champ, J. Marshall, and M. Vorobyev. 2010. Double cones are used for colour discrimination in the reef fish, Rhinecanthus aculeatus. Biol. Lett. 6:537-539.

Pike, T. W., J. D. Blount, B. Bjerkeng, J. Lindström, and N. B. Metcalfe. 2007. Carotenoids, oxidative stress and female mating preference for longer lived males. Proc. Roy. Soc. B. 274:1591-1596.

This article is protected by copyright. All rights reserved. 
R Core Team. 2014. R: A language and environment for statistical computing. R Foundation for Statistical Computing, Vienna. ISBN 3-900051-07-0. Available from http://www. Rproject.org/.

Rohlf, F. J. 2008. TPSDIG, Version 2.11. Department of Ecology and Evolution, State University of New York at Stony Brook. Available from http://life.bio.sunysb.edu/morph/.

Rolff, J. 2002. Bateman's principle and immunity. Proc. Roy. Soc. B. 269:867-872.

Roth, O., J. P. Scharsack, I. Keller, and T. B. H. Reusch. 2011. Bateman's principle and immunity in a sex-role reversed pipefish. J. Evol. Biol. 24:1410-1420.

Rowe, L., and D. Houle. 1996. The lek paradox and the capture of genetic variance by condition dependent traits. Proc. R. Soc. London Ser. B 263:1415-21.

Salzburger, W., T. Mack, E. Verheyen, and A. Meyer. 2005. Out of Tanganyika: genesis, explosive speciation, key-innovations and phylogeography of the haplochromine cichlid fishes. BMC Evol. Biol. 5:1-15.

Salzburger, W., I. Braasch, and A. Meyer. 2007. Adaptive sequence evolution in a color gene involved in the formation of the characteristic egg-dummies of male haplochromine cichlid fishes. BMC Biol. 5:1-13.

Santos, M. E., I. Braasch, N. Boileau, B. S. Meyer, L. Sauteur, A. Böhne, H.-G. Belting, M. Affolter, and W. Salzburger. 2014. The evolution of cichlid fish egg-spots is linked with a cis-regulatory change. Nature Comm. 5:1-11.

This article is protected by copyright. All rights reserved. 
Scharsack, J. P., M. Kalbe, R. Derner, J. Kurtz, and M. Milinski. 2004. Modulation of granulocyte responses in three-spined sticklebacks Gasterosteus aculeatus infected with the tapeworm Schistocephalus solidus. Diseases Aquat. Organ. 59:141-150.

Scharsack, J. P., M. Kalbe, C. Harrod, and G. Rauch. 2007a. Habitat-specific adaptation of immune responses of stickleback (Gasterosteus aculeatus) lake and river ecotypes. Proc. Roy. Soc. B. 274:1523-1532.

Scharsack, J. P., K. Koch, and K. Hammerschmidt. 2007b. Who is in control of the stickleback immune system: interactions between Schistocephalus solidus and its specific vertebrate host. Proc. Roy. Soc. B. 274:3151-3158.

Schwartz, A. K, and A. P. Hendry. 2007. A test for the parallel co-evolution of male colour and female preference in Trinidadian guppies (Poecilia reticulata). Evol Ecol. Res. 9:7190.

Seehausen, O., J. J. M. van Alphen, and F. Witte. 1997. Cichlid fish diversity threatened by eutrophication that curbs sexual selection. Science 277:1808-1811.

Seehausen, O., Y. Terai, I. S. Magalhaes, K. L. Carleton, H. D. J. Mrosse, et al. 2008. Speciation through sensory drive in cichlid fish. Nature 455:620-626.

Sheldon, B. C., and S. Verhulst. 1996. Ecological immunology: costly parasite defences and trade-offs in evolutionary ecology. Trends Ecol. Evol. 11:317-321.

Simons, M. J., A. A. Cohen, and S. Verhulst. 2012. What does carotenoid-dependent coloration tell? Plasma carotenoid level signals immunocompetence and oxidative stress state in birds-A metaanalysis. PLoS ONE 7:e43088.

This article is protected by copyright. All rights reserved. 
Smith, H. G., L. Råberg, T. Ohlsson, M. Granbom, and D. Hasselquist. 2007. Carotenoid and protein supplementation have differential effects on pheasant ornamentation and immunity. J. Evol. Biol. 20:310-319.

Stuart-Fox, D. M., and T. J. Ord. 2004. Sexual selection, natural selection and the evolution of dimorphic coloration and ornamentation in agamid lizards. Proc. Roy. Soc. B. 271:2249-2255.

Svensson, P. A., and B. B. M. Wong. 2011. Carotenoid-based signals in behavioural ecology: a review. Behaviour 148:131-189.

Számadó, S. 2011. The cost of honesty and the fallacy of the handicap principle. Anim. Behav. 81:3-10.

Theis, A., W. Salzburger, and B. Egger. 2012. The function of anal fin egg-spots in the cichlid fish Astatotilapia burtoni. PLoS ONE 7:e29878.

Theis, A., F. Ronco, A. Indermaur, W. Salzburger, and B. Egger. 2014. Adaptive divergence between lake and stream populations of an East African cichlid fish. Mol. Ecol. 23:53045322.

Theis, A., T. Bosia, T. Roth, W. Salzburger, and B. Egger. 2015. Egg-spot and body size asymmetries influence attack strategies in haplochromine cichlid fishes. Beh. Ecol. 26:1512-1519.

Tobler, M. 2006. The eggspots of cichlids: Evolution through sensory exploitation? Zeitschrift für Fischkunde 8:39-46.

This article is protected by copyright. All rights reserved. 
Trivers, R. L. 1972. Parental investment and sexual selection. In: Sexual Selection and the Descent of Man, 1871-1971 (Campbell, B., ed.), p. 136-179. Aldine Press, Chicago, USA.

van Noordwijk, A. J., and G. de Jong. 1986. Acquisition and allocation of resources: their influence on variation in life history tactics. Amer. Nat. 128:137-142.

von Schantz, T., S. Bensch, M. Grahn, D. Hasselquist, H. and Wittzell. 1999. Good genes, oxidative stress and condition-dependent sexual signals. Proc. Roy. Soc. B. 266:1-12.

Vorobyev, M., and D. Osorio. 1998. Receptor noise as a determinant of colour thresholds. Proc. Roy. Soc. B 265:351-358.

Vorobyev, M., R. Brandt, D. Peitsch, S. B. Laughlin, and R. Menzel. 2001. Colour thresholds and receptor noise: Behaviour and physiology compared. Vision Res. 41:639-653.

Wickler, W. 1962. 'Egg-dummies' as natural releasers in mouth-breeding cichlids. Nature 194:1092-1093.

Witeska, M. 2005. Stress in fish-hematological and immunological effects of heavy metals. Electronic J. Ichthyol. 1:35-41.

Wong, B. B. M., U. Candolin, and K. Lindström. 2007. Environmental deterioration compromises socially enforced signals of male quality in three- spined sticklebacks. Am. Nat. 170:184-189.

Zahavi, A. 1975. Mate selection—a selection for a handicap. J. Theoret. Biol. 53:205-214.

Zahavi, A., and A. Zahavi. 1997. The handicap principle: a missing piece of Darwin's puzzle. Oxford University Press, Oxford, UK.

This article is protected by copyright. All rights reserved. 
Zeileis, A. 2004. Econometric computing with HC and HAC covariance matrix estimators. J. Statistical Software 11:1-17.

Zeileis, A. 2006. Object-oriented computation of sandwich estimators. J. Statistical Software $16: 1-16$

Table 1. Multiple regression on distance matrices (MRM) among pairwise differences in egg-spot characteristics, orange ratio, lymphocyte ratio as well as geographic distance. The egg-spot characteristics number, relative average area and coloration were corrected on centroid size before the analyses. The reported p-values for each parameter (orange ratio, lymphocyte ratio and geographic distance) result from combined MRMs including those three parameters.

\begin{tabular}{llll}
\hline egg-spot characteristic & orange ratio & lymphocyte ratio & geographic distance \\
\hline number & 0.2336 & 0.0065 & 0.0744 \\
relative average area & 0.1069 & 0.0076 & 0.1397 \\
relative total area & 0.8409 & 0.7708 & 0.0247 \\
coloration & 0.0082 & 0.1485 & 0.5281 \\
\hline
\end{tabular}

Figure 1. Male secondary sexual trait and populations under investigation. (A) Egg-spots on the anal fin of a male Astatotilapia burtoni. (B) Map showing the 11 sampling localities in the southern part of Lake Tanganyika (squares represent lake and circles stream populations; bathymetric lines are placed at every $100 \mathrm{~m}$ water depth, after Coulter 1991; full names of populations are listed in the grey box).

This article is protected by copyright. All rights reserved. 


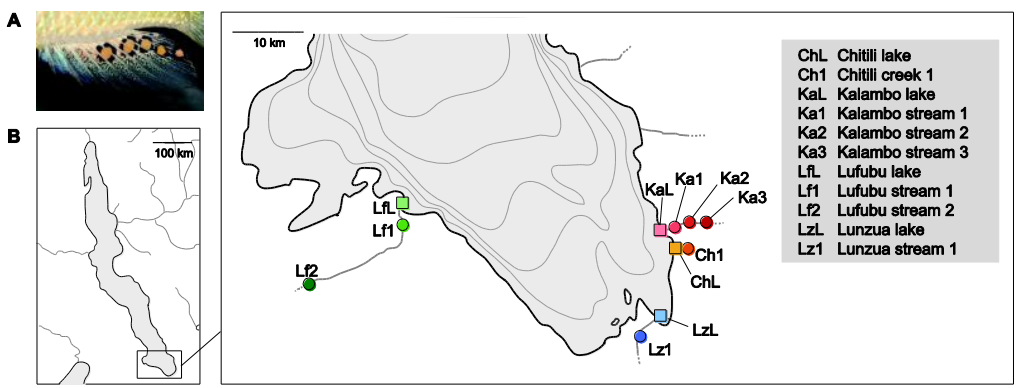

Figure 2. Differences in the four examined egg-spot characteristics measured based on photographs (number, relative average area, relative total area and coloration) between all females and males (A) and among males of the populations within the lake-stream systems (B). Full names of populations are listed in the grey box of Fig. 1. Significance levels: ${ }^{\circ} \mathrm{p}<0$. $1,{ }^{*} \mathrm{p}<0.05, * * \mathrm{p}<0.01$ and $* * * \mathrm{p}<0.001$. Corresponding sample sizes are parenthesized. For each system, populations are ordered on the $\mathrm{x}$-axis with the lake populations on the left followed by the stream population(s).

This article is protected by copyright. All rights reserved. 
A
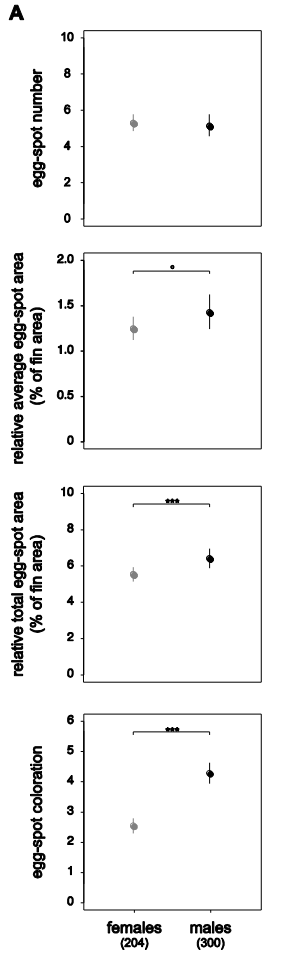

B
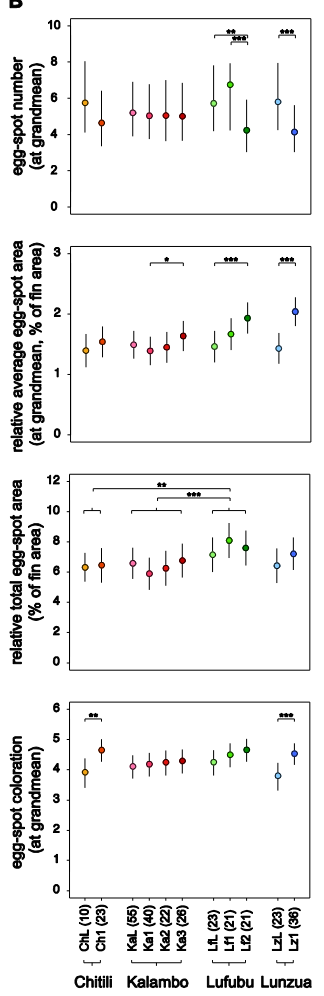

Figure 3. Differences in egg-spot characteristics. (A) PCA-biplot of all populations measured based on the examined egg-spot characteristics measured on the photographs (number, relative average area, relative total area and coloration). The indicated dots/squares represent the mean for all males per population. Sample sizes are the same as reported in Fig. 2B. (B) Color distances resulting from the visual models including the orange ratio for $30 \mathrm{~cm}$ below surface. Sample sizes are parenthesized. For each system, populations are ordered on the $\mathrm{x}$-axis with the lake populations on the left followed by the stream population(s).

This article is protected by copyright. All rights reserved. 
Figure 3
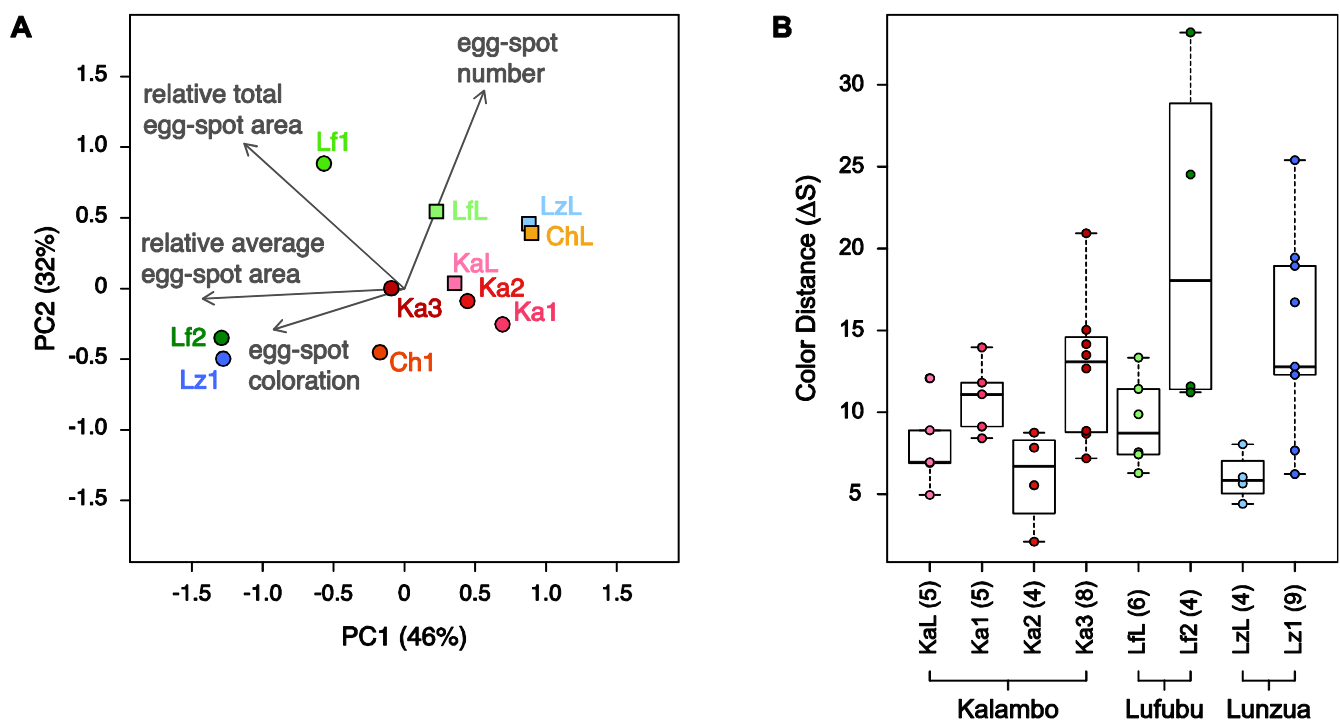

Figure 4. Boxplots of lymphocyte ratios and average orange ratio values (indicated by triangles; average change in orange ratio per $10 \mathrm{~cm}$ calculated from the deepest available measurement) per population (note that for the populations $\mathrm{ChL}$ and $\mathrm{Ch} 1$, no data on lymphocyte ratio was available). For each system, populations are ordered on the x-axis with the lake populations on the left followed by the stream population(s).

Figure 4

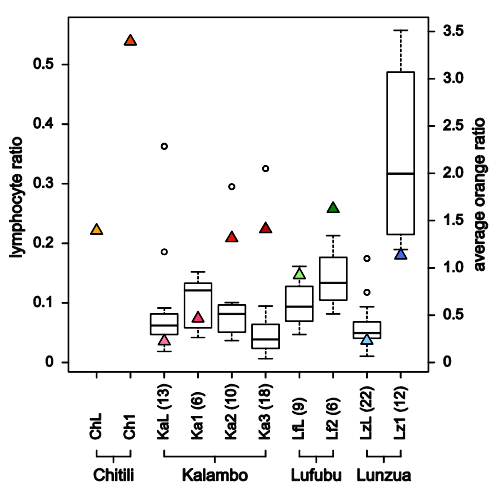

This article is protected by copyright. All rights reserved. 